\title{
Association between sequence variations of the Mediterranean fever gene and the risk of migraine: a case-control study
}

This article was published in the following Dove Press journal:

Neuropsychiatric Disease and Treatment

29 August 2016

Number of times this article has been viewed

\author{
Salih Coșkun' \\ Sefer Varol ${ }^{2}$ \\ Hasan H Özdemir ${ }^{2}$ \\ Sercan Bulut Çelik ${ }^{3}$ \\ Metin Balduz ${ }^{4}$ \\ Mehmet Akif Camkurt ${ }^{5}$ \\ Abdullah Çim' \\ Demet Arslan² \\ Mehmet Uğur Çevik ${ }^{2}$ \\ 'Department of Medical Genetics, \\ ${ }^{2}$ Department of Neurology, Faculty of \\ Medicine, Dicle University, Diyarbakir, \\ ${ }^{3}$ Family Health Center, Batman, \\ ${ }^{4}$ Department of Neurology, Sanlıurfa \\ Education and Research Hospital, \\ Sanlıurfa, ${ }^{5}$ Department of Psychiatry, \\ Afsin State Hospital, Kahramanmaraș, \\ Turkey
}

\begin{abstract}
Migraine pathogenesis involves a complex interaction between hormones, neurotransmitters, and inflammatory pathways, which also influence the migraine phenotype. The Mediterranean fever gene $(M E F V)$ encodes the pyrin protein. The major role of pyrin appears to be in the regulation of inflammation activity and the processing of the cytokine prointerleukin-1 $\beta$, and this cytokine plays a part in migraine pathogenesis. This study included 220 migraine patients and 228 healthy controls. Eight common missense mutations of the MEFV gene, known as M694V, M694I, M680I, V726A, R761H, K695R, P369S, and E148Q, were genotyped using real-time polymerase chain reaction with $5^{\prime}$ nuclease assays, which include sequence specific primers, and probes with a reporter dye. When mutations were evaluated separately among the patient and control groups, only the heterozygote E148Q carrier was found to be significantly higher in the control group than in the patient group ( $P=0.029$, odds ratio [95\% confidence interval] $=0.45[0.21-0.94]$ ). In addition, the frequency of the homozygote and the compound heterozygote genotype carrier was found to be significantly higher in patients $(\mathrm{n}=8,3.6 \%)$ than in the control group $(\mathrm{n}=1,0.4 \%)(P=0.016$, odds ratio [ $95 \%$ confidence interval] $=8.57$ [1.06-69.07]). However, there was no statistically significant difference in the allele frequencies of $M E F V$ mutations between the patients and the healthy control group $(P=0.964)$. In conclusion, the results of the present study suggest that biallelic mutations in the $M E F V$ gene could be associated with a risk of migraine in the Turkish population. Moreover, $M E F V$ mutations could be related to increased frequency and short durations of migraine attacks $(P=0.043$ and $P=0.021$, respectively). Future studies in larger groups and expression analysis of $M E F V$ are required to clarify the role of the $M E F V$ gene in migraine susceptibility.
\end{abstract}

Keywords: $M E F V$ gene, headache, Familial Mediterranean fever (FMF), biallelic mutations, pyrin (or marenostrin), aura, single nucleotide polymorphisms

\section{Introduction}

Migraine is a disabling neurological condition that is commonly observed to occur in an episodic manner. In many cases, migraine attacks begin centrally, leading to classical neurological symptoms, including prodromes and aura, followed by a headache phase. The pathophysiology of migraine is unclear, but several studies have demonstrated abnormalities in pain-processing mechanisms. ${ }^{1}$ In addition, inflammation has long been suggested to play a role in migraine. ${ }^{2}$ Various vasoactive neuropeptides have been released from trigeminal and parasympathetic perivascular fibers during neurogenic inflammation. The release of these neuropeptides leads to vasodilation, plasma protein extravasation, and the release of proinflammatory mediators. ${ }^{3}$ These molecules contribute to the sensitization of nociceptors and induce inflammation with
Correspondence: Salih Coșkun Department of Medical Genetics, Faculty of Medicine, Dicle University, 21280 Sur, Diyarbakır, Turkey

Tel +90412248800 I

Fax +90 4I2 2488440

Email scoskun9@gmail.com 
the activation of local immune cells, including brain mast cells. ${ }^{4}$ Therefore, the headache phase begins with consequential activation of meningeal nociceptors at the origin of the trigeminovascular system. ${ }^{1}$

Familial Mediterranean fever (FMF) is characterized by recurrent short episodes of inflammation and polyserositis, including fever, peritonitis, synovitis, pleuritis, headache, and meningitis accompanied by pain. ${ }^{5-7}$ FMF has an autosomal recessive inheritance; it is mostly seen in eastern Mediterranean populations, and it is especially frequent among Turks, Armenians, non-Ashkenazi Jews, and Arabs. ${ }^{8}$ In 1997, French and international consortia identified the Mediterranean fever gene ( $M E F V)$ as being responsible for FMF. FMF occurs due to recessive mutations in the $M E F V$ gene, which is located on the short arm of chromosome 16 , consisting of ten exons. This gene encodes a protein comprising 781 amino acids known as pyrin (or marenostrin). ${ }^{9}$ The type and combination of the mutations define a severely or weakly expressed phenotype; however, subjects carrying two mutation alleles may not express the disease. ${ }^{10}$ At present, over 300 different FMF-associated sequence variants have been reported in the $M E F V$ gene. ${ }^{11}$ The most prevalent mutations are M680I, M694V, M694I, and V726A in exon 10 and E148Q in exon 2. Together, these have been found to be responsible for over $85 \%$ of all FMF cases in the Middle East. ${ }^{12-14}$ The M694V mutation was reported to have a relative association with the severe phenotype, whereas the E148Q mutation has been reported to result in a milder or less penetrant disease course. ${ }^{15,16}$

Pyrin is expressed in polymorphonuclear cells, cytokineactivated monocytes, dendritic cells, and synovial fibroblasts. Interleukin- $1 \beta$ may play a part in migraine pathogenesis, and pyrin has been suggested to play a role in the regulation of inflammation activity and pro-interleukin- $1 \beta$ processing. ${ }^{17}$ Mutations in the $M E F V$ gene are responsible for innate immunity disorders, which are associated with activation in the interleukin-1 $\beta$ pathway, leading to sustained activation of inflammatory cascade and severe inflammation. ${ }^{18,19}$ In addition to interleukin- $1 \beta$ changes in FMF, serum levels of tumor necrosis factor $\alpha$ (TNF- $\alpha$ ), interleukin-6, interleukin-8, and soluble interleukin-2R are significantly increased during FMF attacks. ${ }^{12}$ Similarly, increases in serum TNF- $\alpha$, interleukin-1 $\beta$, interleukin-2, and interleukin-6 level have been previously described in patients with migraine..$^{20,21}$ Therefore, it seems that a proinflammatory cytokine expression profile is related to migraine pathogenesis. ${ }^{20,21}$

Some clinical characteristics and positive familial history of FMF and migraine seem to be similar. In addition,
FMF and migraine both have recurrent, periodic, painful symptoms. In the literature, a number of clinical observations have long suggested a possible relationship between headache and FMF.,22-26 Furthermore, a clinical study reported that the prevalence of migraine in patients with FMF was $29.1 \%$ in the Turkish population. ${ }^{6}$ Moreover, it has been reported that the presence of $M E F V$ gene mutations might be a susceptibility factor for various inflammatory diseases. ${ }^{27-29}$ To the best of our knowledge, no study has investigated the association between mutations in the $M E F V$ gene and migraine disease. We hypothesized that mutations in the $M E F V$ gene may contribute to the development of migraine disease. Considering the high frequency of FMF in Turkey, it is important to investigate $M E F V$ mutations and the effects of these mutations on migraine. Therefore, we researched whether the $M E F V$ gene could be involved in migraine pathogenesis. A case-control study was designed to compare the frequency of mutations and genotypes in the $M E F V$ gene between migraine patients and healthy controls and to compare disease severity between patients with and without mutations.

\section{Materials and methods Study population}

This study was carried out according to the principles of the Declaration of Helsinki. The study was approved by the Ethics Committee of Dicle University, Faculty of Medicine, and each subject provided written informed consent. The study group consisted of 220 unselected and unrelated patients with migraine. All migraine patients who registered at the Department of Neurology outpatient clinic at Dicle University, Faculty of Medicine, in Diyarbakir, Turkey, between January 2014 and January 2015, were included in this study. Migraine was diagnosed according to the International Classification of Headache Disorders criteria. ${ }^{30}$ Patients with obesity (body mass index $>30$ ), diabetes, or other neurologic or psychiatric disorders were excluded from this study. None of the patients reported any familial history of FMF or classical FMF symptoms, such as recurrent fever or abdominal pain. The control group consisted of 228 volunteers, who applied to the other outpatient clinic at Dicle University. All participants provided a complete medical history and underwent a physical examination. The control subjects were genetically unrelated to the patients, and they showed no clinical evidence of migraine; furthermore, they had no previous or current history of migraine; no familial history of migraine; and no known neurologic, psychiatric, or rheumatologic clinical features indicating FMF. 
In addition, they had no history of diabetes mellitus, hypertension, obesity (body mass index $>30$ ), or organic or genetic disorders. The mean age, sex, and ethnicity of the control group were matched with those of the study group. All participants were of Turkish origin and were from the same geographical area (the southeastern region of Turkey). The migraine patients were assigned to two subgroups: with $M E F V$ gene mutation and without $M E F V$ gene mutation. Demographic and clinical features were compared between the two subgroups.

\section{DNA extraction and genotyping}

Whole blood samples $(2 \mathrm{~mL})$ were taken into ethylenediaminetetraacetic acid-treated tubes and stored at $-20^{\circ} \mathrm{C}$. The isolation of genomic DNA was performed using SNPure Genomic DNA isolation kit according to manufacturer's instructions (SNP Biotecnology, Ankara, Turkey). The DNA concentration was determined using a Nano-Drop spectrophotometer (Thermo Fisher Scientific, Waltham, MA, USA), and samples were stored at $-20^{\circ} \mathrm{C}$ until polymerase chain reaction (PCR). In the present study, genotyping was performed for the most frequent eight missense mutations: M694V (p.Met694Val, c.2080A $>$ G, rs61752717), M694I (p.Met694Ile, c.2082G >A, rs28940578), M680I (p.Met680Ile, c.2040G >C, rs28940580), $V 726 A$ (p.Val726Ala, c.2177T $>$ C, rs28940579), $R 761 H$ (p.Arg761His, c.2282G >A, rs104895097), and K695R (p.Lys695Arg, c.2084A $>$ G, rs104895094) in exon 10; P369S (p.Pro369Ser, c.1105C $>$ T, rs11466023) in exon 3; and $E 148 Q$ (p.Glu148Gln, c.442G $>$ C, rs3743930) in exon 2 of the $M E F V$ gene. To detect the mutation, we used an SNP FMF real-time PCR kit (SNPFMF-8). This kit contains readyto-use patented wild-type and mutant master mixes for each mutation, and genotyping was performed using the $5^{\prime}$ nuclease method. The master mixes contain sequence-specific primers and probes as well as an internal control targeting glyceraldehyde 6-phosphate dehydrogenase labeled with HEX/ JOE dye. The probes in the master mixes carry reporter dye (FAM) attached at the $5^{\prime}$-end and quencher dye attached at the 3 -end. The quencher dye absorbs and suppresses the emission of the reporter dye and prevents the elongation of the probe, such as a primer. During PCR, the $5^{\prime}$ nuclease activity cleaves the probe and releases the reporter dye, and a fluorescent signal is generated by the cleaved reporter dye. This reaction occurs only for the probes that are hybridized with the target sequence. As the amount of the amplification product accumulates, the fluorescent signal increases linearly, and this increase is detected by the device simultaneously. Therefore, when the fluorescent signal is obtained only from the wild-type mixture, the sample is accepted as wild type; when the fluorescent signal is obtained from the wildtype and mutant PCR mixtures, the sample is accepted as heterozygous; and when the fluorescent signal is obtained only from the mutant PCR mixture, the sample is accepted as homozygous mutant. For each reaction, $20.5 \mu \mathrm{L}$ of the master mix, $0.3 \mu \mathrm{L}$ of the hot start Taq DNA polymerase, and $4.5 \mu \mathrm{L}(60-100 \mathrm{ng})$ of genomic DNA were used. PCR conditions were one cycle at $95^{\circ} \mathrm{C}$ for 10 minutes (enzyme activation), 32 cycles of two steps at $95^{\circ} \mathrm{C}$ for 15 seconds (denaturation), and $62^{\circ} \mathrm{C}$ (annealing) for 1 minute. PCR was performed using real-time PCR systems (Applied Biosystems 7500 system, ABI, USA).

\section{Statistical analysis}

The distributions of the genotype and polymorphism between migraine and control groups were compared by using $\chi^{2}$ test or Fisher's exact test. For the age variable, which obtained a continuous value, the normality test was conducted using the Kolmogorov-Smirnov test. The age variable was compared between the two groups using a Student's $t$-test. The data were given as mean \pm standard deviation (SD) and frequency. Two-tailed tests were used unless otherwise stated. Goodness of fit $\chi^{2}$ test was used to assess deviations from Hardy-Weinberg equilibrium in control group. A $P$-value of $<0.05$ was considered to show a statistically significant result. Odds ratios (ORs) and 95\% confidence intervals (CIs) were also calculated. Statistical analyses were performed with SPSS 15.0 (SPSS Inc., Chicago, IL, USA). The power of the study was calculated using $\mathrm{G}^{*}$ Power software, version 3.1.9. ${ }^{31}$ With the current sample size, the achieved power of the study was 0.67 for $\chi^{2}=5.816(d f=1, \mathrm{OR}=8)$, and the effect size was $w=0.114$.

\section{Results}

The mean age of the 220 subjects in the patient group (109 males and 111 females) was $30.46 \pm 10.27$ SD, while the mean age of the 228 subjects in the control group (133 males and 95 females) was 31.19 $\pm 9.26 \mathrm{SD}$. There was no significant difference in age or sex between the groups $(P=0.430$ and $P=0.062$, respectively). The number of patients who experienced migraine with aura was 103 (46.82\%), and the number of patients who experienced migraine without aura was 117 (53.18\%). In addition, 52 patients (23.64\%) stated that they had a positive familial history, but 168 patients $(76.36 \%)$ had no familial history. The mean age at the onset of the disease was 26.25 \pm 9.911 SD in the migraine group. The frequency and duration of attacks in the migraine group 
Table I Demographic and clinical features of study participants

\begin{tabular}{lll}
\hline Parameters & $\begin{array}{l}\text { Migraine patients } \\
(\mathbf{n = 2 2 0})\end{array}$ & $\begin{array}{l}\text { Healthy subjects } \\
(\mathbf{n}=\mathbf{2 2 8})\end{array}$ \\
\hline $\begin{array}{l}\text { Age (years) (mean } \pm \text { SD) } \\
\text { Sex (n, \%) }\end{array}$ & $30.46 \pm 10.27$ & $31.19 \pm 9.26$ \\
$\quad$ Female & $111(50.45)$ & $95(41.67)$ \\
$\quad$ Male & $109(49.55)$ & $133(58.33)$ \\
Migraine types (n, \%) & $103(46.82)$ & \\
MA & $117(53.18)$ & \\
MO & $26.25 \pm 9.911$ & \\
Age at onset of migraine (years) & $4.23 \pm 3.40$ & \\
Attack frequency (attack/monthly) & $22.96 \pm 15.86$ & \\
Attack duration (hours) & & \\
Familial history of migraine (n, \%) & $52(23.64)$ & \\
Yes & $168(76.36)$ & \\
No &
\end{tabular}

Abbreviations: MA, migraine with aura; MO, migraine without aura; SD, standard deviation.

were $4.23 \pm 3.40$ attacks per month and $23.94 \pm 15.61$ hours, respectively. The demographic and clinical characteristics of the groups are shown in Table 1. All the analyzed MEFV mutations were in Hardy-Weinberg equilibrium $(P>0.05)$.

We evaluated the sequencing results for eight missense mutations (M694V, M694I, V726A, M680I, R761H, K695R, P369S, and E148Q). We identified seven missense mutations in 220 patients and 228 healthy controls. The M694I mutation was not observed in both groups. MEFV gene mutations were detected in 30 (13.6\%) patients. Of the patients, 22 had a single mutation and eight had two copied mutations. Three homozygous and five compound heterozygous mutations were observed in the patients. The frequencies of E148Q, M694V, V726A, and R761H mutation carriage in patients with migraine were $5.0 \%, 1.4 \%, 1.4 \%$, and $0.9 \%$, respectively. In addition, the allele frequencies of E148Q, M694V, V726A, and R761H were 4.3\%, 1.4\%, $0.9 \%$, and $0.9 \%$, respectively. In the control group, mutation analysis showed that $38(16.7 \%)$ of the subjects had at least one mutated $M E F V$ allele. Furthermore, 37 individuals had a single mutation, and only one individual had compound heterozygous mutations (V726A/R761H). The frequencies of E148Q, V726A, R761H, and P369S mutation carriage were $10.5 \%, 2.2 \%, 1.8 \%$, and $0.9 \%$, respectively. In addition, the allele frequencies of E148Q, V726A, R761H, and P369S were $5.3 \%, 1.3 \%, 1.1 \%$, and $0.4 \%$, respectively. No homozygous mutations were detected in the healthy controls (Table 2).

The difference in total $M E F V$ mutation carriage rates and allele frequencies between the migraine and control groups was not statistically significant. However, the frequencies of homozygote and compound heterozygote genotype carrier were significantly higher in the patient group (eight cases, $3.6 \%)$ than in the control group (one control, $0.4 \%)(P=0.016$, OR $[95 \% \mathrm{CI}]=8.57$ [1.06-69.07]). When mutations were evaluated separately among the patient and control groups, only heterozygote E148Q was significantly higher in the controls than in the patients $(P=0.029$, OR $[95 \% \mathrm{CI}]=0.45$ [0.21-0.94]). The allele and genotype frequencies for the migraine and control groups are shown in Tables 2 and 3.

The analysis of the relationships between $M E F V$ mutations and clinical manifestations in patients with migraine is presented in Table 4. No significant results were observed between the carrier and non-carrier groups in terms of age, sex, presence or absence of aura, familial history, age of onset of migraine, and visual analog scale. The migraine attack frequency in patients with $M E F V$ mutations was significantly more than it was in those without any mutation $(P=0.043)$.

\section{Discussion}

In the case-control study, we investigated whether the hotspot mutations (M694V, M694I, M680I, V726A, R761H, $\mathrm{K} 695 \mathrm{R}, \mathrm{P} 369 \mathrm{~S}$, and E148Q) in the $M E F V$ gene were associated with a risk of migraine disease in a Turkish population. This is the first study to investigate the effect of mutations in the $M E F V$ gene on the risk of developing migraine. There was a statistically significant association between the homozygous or compound heterozygous mutations in the $M E F V$ gene and migraine. Our findings suggest that biallelic mutations of the $M E F V$ gene could be involved in migraine pathogenesis in our Turkish population.

Migraine is a common neurological condition involving recurrent attacks of severe, pulsating, unilateral headaches 
Table 2 Distribution of MEFV mutations in patients with migraine compared with healthy controls

\begin{tabular}{|c|c|c|c|c|c|}
\hline Genotypes and alleles (n, \%) & $\begin{array}{l}\text { Migraine patients } \\
(n=220)\end{array}$ & $\begin{array}{l}\text { Healthy subjects } \\
(n=228)\end{array}$ & $P$-value & $d f$ & OR $(95 \% \mathrm{CI})$ \\
\hline \multicolumn{6}{|l|}{ Number of heterozygous mutations } \\
\hline $\mathrm{M} 694 \mathrm{~V} / \mathrm{Wt}$ & $3(1.4)$ & $\mathrm{I}(0.4)$ & 0.364 & I & $3.14(0.29-78.87)$ \\
\hline V726A/Wt & $3(1.4)$ & $5(2.2)$ & 0.759 & I & $0.62(0.12-3.00)$ \\
\hline $\mathrm{El} 48 \mathrm{Q} / \mathrm{Wt}$ & II (5.0) & $24(10.5)$ & 0.029 & $\mathbf{I}$ & $0.45(0.21-0.94)$ \\
\hline $\mathrm{R} 76 \mathrm{IH} / \mathrm{Wt}$ & $2(0.9)$ & $4(1.8)$ & 0.685 & I & $0.5 I(0.06-3.29)$ \\
\hline $\mathrm{P} 369 \mathrm{~S} / \mathrm{Wt}$ & I $(0.5)$ & $2(0.9)$ & 1.00 & I & $0.52(0.02-7.29)$ \\
\hline $\mathrm{K} 695 \mathrm{R} / \mathrm{Wt}$ & I $(0.5)$ & I $(0.4)$ & 1.00 & I & $1.04(0.00-38.11)$ \\
\hline $\mathrm{M} 680 \mathrm{I} / \mathrm{Wt}$ & I $(0.5)$ & - & 0.491 & I & \\
\hline Subtotal & $22(10.0)$ & $37(16.2)$ & 0.051 & I & $0.57(0.3 \mathrm{I}-\mathrm{I} .04)$ \\
\hline \multicolumn{6}{|c|}{ Number of homozygous/compound heterozygous mutations } \\
\hline EI48Q/EI48Q & $2(0.9)$ & - & - & & \\
\hline $\mathrm{EI} 48 \mathrm{Q} / \mathrm{R} 76 \mathrm{IH}$ & $2(0.9)$ & - & - & & \\
\hline M694V/M694V & I $(0.5)$ & - & - & & \\
\hline El48Q/K695R & $\mathrm{I}(0.5)$ & - & - & & \\
\hline M694V/EI48Q & $\mathrm{I}(0.5)$ & - & - & & \\
\hline V726A/P369S & $\mathrm{I}(0.5)$ & - & - & & \\
\hline V726A/R76IH & - & $\mathrm{I}(0.4)$ & - & & \\
\hline Subtotal & $8(3.6)$ & I (0.4) & 0.016 & I & 8.57 (1.06-69.07) \\
\hline Total genotypes & $30(13.6)$ & $38(16.7)$ & 0.371 & I & $0.79(0.45-1.37)$ \\
\hline
\end{tabular}

Note: Results that are statistically significant are shown in bold.

Abbreviations: $\mathrm{Cl}$, confidence interval; $d f$, degrees of freedom; MEFV, Mediterranean fever gene; OR, odds ratio; Wt, wild-type allele.

with or without related symptoms, including nausea, vomiting, and photophobia..$^{32}$ The genetic component of migraine has been confirmed by population-based family studies, and a positive familial history increased the risk of migraine..$^{33}$ FMF is an inherited disease that presents in an autosomal recessive manner. During FMF attacks, neurological complications are also reported. In various studies, the prevalence of headache has been reported as approximately $5 \%$ to $20 \%$ among FMF patients. ${ }^{7,23,25,26}$ Gedalia et a ${ }^{34}$ reported that of 101 patients, ten experienced headaches during FMF attacks. In a recent study, Kishida et a ${ }^{25}$ reported that headache was present in $19.8 \%$ of patients with FMF in Japan. In three studies conducted in Turkey, the frequency of headaches in FMF patients was reported as $8.1 \%, 5.1 \%$, and $19.8 \%$, respectively. ${ }^{7,23,26}$ Furthermore, in a large Turkish study of
378 FMF cases, Uluduz et $\mathrm{al}^{6}$ found that $29.5 \%$ of subjects with FMF reported having migraine and $37.6 \%$ reported probable migraine.

The migraine pathophysiology has not been clarified yet. A number of neural and vascular mechanisms have been suggested for increased susceptibility to migraine. One of these mechanisms involves peripheral inflammation interacting with neural structures, which activates the meningeal nociceptors in the trigeminovascular system. The pyrin protein is expressed in the inflammatory cells, including dendritic cells, monocytes, and granulocytes. ${ }^{35}$ It has been suggested that pyrin regulates the pro-interleukin- $1 \beta$ maturation into interleukin- $1 \beta$, catalyzed by caspase- 1 . In addition, pyrin likely regulates nuclear factor- $\kappa \mathrm{B}$ activation and apoptosis. ${ }^{17,19}$ Nuclear factor- $\kappa B$ is expressed in all types

Table 3 The allele frequency of migraine and control groups

\begin{tabular}{|c|c|c|c|c|c|c|c|}
\hline \multirow[t]{2}{*}{ Alleles } & \multirow[t]{2}{*}{$P$-value } & \multirow[t]{2}{*}{$d f$} & \multirow[t]{2}{*}{ OR (95\% CI) } & \multicolumn{2}{|c|}{ Migraine $(n=440)$} & \multicolumn{2}{|c|}{ Control $(n=456)$} \\
\hline & & & & $\mathbf{n}$ & $\%$ & $\mathbf{n}$ & $\%$ \\
\hline M694V & 0.064 & 1 & $6.29(0.75-139.2)$ & 6 & $\mathrm{I} .4$ & I & 0.2 \\
\hline V726A & 0.752 & 1 & $0.69(0.16-2.77)$ & 4 & 0.9 & 6 & 1.3 \\
\hline EI48Q & 0.508 & I & $0.81(0.42-1.57)$ & 19 & 4.3 & 24 & 5.3 \\
\hline R76IH & 0.778 & I & $0.83(0.19-3.56)$ & 4 & 0.9 & 5 & I.I \\
\hline P369S & 1.00 & I & $1.04(0.10-10.30)$ & 2 & 0.5 & 2 & 0.4 \\
\hline K695R & 0.617 & 1 & $2.08(0.15-58.02)$ & 2 & 0.5 & I & 0.2 \\
\hline M680I & - & - & - & I & 0.2 & - & - \\
\hline Total & 0.964 & I & I.0I (0.62-1.65) & 38 & 8.6 & 39 & 8.6 \\
\hline
\end{tabular}

Abbreviations: $\mathrm{Cl}$, confidence interval; $d f$, degrees of freedom; OR, odds ratio. 
Table 4 Comparison of demographic features and clinical manifestations between MEFV mutation carriers and non-carriers

\begin{tabular}{|c|c|c|c|}
\hline \multirow[t]{2}{*}{ Parameters } & \multicolumn{2}{|l|}{ Mutations } & \multirow[t]{2}{*}{$P$-value } \\
\hline & Carrier $(n=30)$ & Non-carrier $(n=190)$ & \\
\hline Age (years) (mean $\pm S D)$ & $29.93 \pm 13.55$ & $30.55 \pm 9.70$ & 0.762 \\
\hline \multicolumn{4}{|l|}{$\operatorname{Sex}(n, \%)$} \\
\hline Female & $12(40.0)$ & $99(52.10)$ & \multirow[t]{2}{*}{0.218} \\
\hline Male & $18(60.0)$ & 91 (47.90) & \\
\hline \multicolumn{4}{|l|}{ Migraine types (n, \%) } \\
\hline $\mathrm{MA}$ & 14 (46.7) & $89(46.8)$ & \multirow[t]{2}{*}{0.985} \\
\hline MO & $16(53.3)$ & $101(53.2)$ & \\
\hline \multicolumn{4}{|l|}{ Familial history of migraine (n, \%) } \\
\hline Yes & $8(26.7)$ & $44(23.2)$ & \multirow[t]{2}{*}{0.674} \\
\hline No & $22(73.3)$ & $146(76.8)$ & \\
\hline Age at onset of migraine (years) & $24.77 \pm 10.05$ & $26.48 \pm 9.89$ & 0.379 \\
\hline Attack frequency (attack/monthly) & $5.40 \pm 4.48$ & $4.05 \pm 3.17$ & 0.043 \\
\hline Attack duration (hours) & $16.77 \pm 16.30$ & $23.94 \pm|5.6|$ & 0.021 \\
\hline Visual analog scale & $8.63 \pm 1.24$ & $8.63 \pm 1.03$ & 0.993 \\
\hline
\end{tabular}

Note: Results that are statistically significant are shown in bold.

Abbreviations: MA, migraine with aura; MO, migraine without aura; MEFV, Mediterranean fever gene; SD, standard deviation.

of cells, and it plays a crucial role in the regulation of inflammatory cytokine production, including interleukin-1 $\beta$, interleukin-6, and TNF- $\alpha .{ }^{12,18,19}$ Therefore, pyrin plays an important role in the regulation of innate immunity and inflammation. It has been reported that cytokines including interleukin-1 $\beta$, interleukin-6, and TNF- $\alpha$ play important roles in the pathogenesis of migraine and that they increase during migraine attacks. ${ }^{20,21}$ Due to the absence of a pyrinassociated anti-inflammatory effect, $M E F V$ gene mutations could be responsible for the severity of the disease in patients. Therefore, $M E F V$ mutations could be responsible for increased frequencies of migraine attacks. In our study, we did not observe an association between $M E F V$ gene mutations and migraine pathogenesis. However, chronic inflammation in migraine patients may enhance the susceptibility of the central nervous system to external and internal stimulants that trigger migraine attacks. Although the trigeminovascular system has been suggested to play a role in the chronic inflammatory activation, the cause of this has not been clarified yet. ${ }^{1,4,36}$

In the healthy Turkish population, the $M E F V$ mutation carrier rate has been reported as $20 \%$ to $27 \%$ in previous studies. ${ }^{8,37}$ Moreover, the carrier frequency has been reported as $12 \%$ for E148Q, 3\% for M694V, and 2\% for V726A in the healthy population. ${ }^{38}$ In our study, the carrier rate was $16.2 \%$, and E148Q was the most common mutation, with a frequency of $10.5 \%$ in the controls. This rate is similar to those found in other studies. On the other hand, we detected that the heterozygous E148Q genotype was significantly higher in healthy controls $(n=24,10.5 \%)$ compared to the patient group $(\mathrm{n}=11,5.0 \%)(P=0.029$, OR [95\% CI] $=0.45$ [0.21-0.94]). The significance of the E148Q alteration as a disease-causing mutation or as a polymorphism is still controversial. It is generally accepted that E148Q is associated with a mild phenotype. However, E148Q has also been considered a polymorphism rather than a disease-causing mutation, and even the presence of homozygosity for E148Q may not be sufficient for developing clinical disease. ${ }^{16}$ The present results support the finding that E148Q has little or no effect on the phenotype or on overall inflammatory disorders, such as FMF and other conditions.

The exon 10 of the $M E F V$ gene includes mutations with high frequency, and it is located in the B30.2 domain of the pyrin. This domain participates in protein interactions, which are important to the normal biochemical function of the pyrin. ${ }^{17}$ Therefore, these mutations represent diseasecausing mutations such as M694V. The M694V mutation has been reported to have an association with a more severe phenotype. ${ }^{15}$ In our study, we did not observe any association between the M694V mutation and migraine. However, a relatively higher frequency was observed for the M694V mutation in migraine patients $(n=3,1.4 \%)$ than in the controls $(\mathrm{n}=1,0.4 \%)$.

Some limitations of the present study should be mentioned. First, our sample size was not sufficient to have confidence in the results, which is reflected in the low power obtained. Second, we genotyped a limited number of mutations in the $M E F V$ gene. Third, the imbalance between the number of 
patients with and without mutations in the $M E F V$ gene in the patient subgroups favors patients without a mutation.

In conclusion, the results of the present study suggest that biallelic mutations in the $M E F V$ gene could be associated with a risk of migraine in the Turkish population. Moreover, $M E F V$ mutations could be related to increased attack frequencies and shorter durations of attacks in migraine disease. However, we did not observe any significant association between the allele frequencies of $M E F V$ mutations and migraine disease. Future studies in larger groups and expression analysis of pyrin levels are required to clarify the role of the $M E F V$ gene in migraine susceptibility. Further studies are also required to confirm these findings in different ethnic populations.

\section{Acknowledgment}

This research article is supported by Dicle University Scientific Research Projects Coordination Office (DUBAP, Project No 14-TF-106).

\section{Disclosure}

The authors report no conflicts of interest in this work.

\section{References}

1. Noseda R, Kainz V, Borsook D, Burstein R. Neurochemical pathways that converge on thalamic trigeminovascular neurons: potential substrate for modulation of migraine by sleep, food intake, stress and anxiety. PLoS One. 2014;9(8):e103929.

2. Eising E, Datson NA, van den Maagdenberg AMJM, Ferrari MD. Epigenetic mechanisms in migraine: a promising avenue? BMC Med. 2013;11:26.

3. Cseh A, Farkas KM, Derzbach L, et al. Lymphocyte subsets in pediatric migraine. Neurol Sci. 2013;34(7):1151-1155.

4. Theoharides TC, Donelan J, Kandere-Grzybowska K, Konstantinidou A. The role of mast cells in migraine pathophysiology. Brain Res Brain Res Rev. 2005;49(1):65-76.

5. Berkun Y, Eisenstein E, Ben-Chetrit E. FMF - clinical features, new treatments and the role of genetic modifiers: a critical digest of the 2010-2012 literature. Clin Exp Rheumatol. 2012;30(3 Suppl 72):S90-S95.

6. Uluduz D, Tavsanli ME, Uygunoğlu U, et al. Primary headaches in pediatric patients with chronic rheumatic disease. Brain Dev. 2014;36(10):884-891.

7. Inal A, Yilmaz M, Kendirli SG, Altintas DU, Karakoc GB. The clinical and genetical features of 124 children with Familial Mediterranean fever: experience of a single tertiary center. Rheumatol Int. 2009;29(11): 1279-1285.

8. Touitou I. The spectrum of Familial Mediterranean Fever (FMF) mutations. Eur J Hum Genet. 2001;9(7):473-483.

9. French FMF Consortium. A candidate gene for familial Mediterranean fever. Nat Genet. 1997;17(1):25-31.

10. Ben-Chetrit E. Familial Mediterranean fever (FMF) and renal AA amyloidosis - phenotype-genotype correlation, treatment and prognosis. J Nephrol. 2003;16(3):431-434.

11. Touitou I, Lesage S, McDermott M, et al. Infevers: an evolving mutation database for auto-inflammatory syndromes. Hum Mutat. 2004;24(3): 194-198.
12. Ben-Chetrit E, Touitou I. Familial Mediterranean fever in the world. Arthritis Rheum. 2009;61(10):1447-1453.

13. Uluca Ü, Ece A, Şen V, et al. High frequency of E148Q sequence variation in children with familial Mediterranean fever in southeast Turkey. Arch Argent Pediatr. 2015;113(2):133-139.

14. Coşkun S, Ustyol L, Bayram Y, et al. The spectrum of MEFV gene mutations and genotypes in Van province, the eastern region of Turkey, and report of a novel mutation (R361T). Gene. 2015;562(1):128-131.

15. Ben-Chetrit E, Lerer I, Malamud E, Domingo C, Abeliovich D. The E148Q mutation in the MEFV gene: is it a disease-causing mutation or a sequence variant? Hum Mutat. 2000;15(4):385-386.

16. Tchernitchko D, Legendre M, Cazeneuve C, Delahaye A, Niel F, Amselem S. The E148Q MEFV allele is not implicated in the development of familial Mediterranean fever. Hum Mutat. 2003;22(4):339-340.

17. Papin S, Cuenin S, Agostini L, et al. The SPRY domain of Pyrin, mutated in familial Mediterranean fever patients, interacts with inflammasome components and inhibits proIL-1beta processing. Cell Death Differ. 2007;14(8):1457-1466.

18. Chae JJ, Cho YH, Lee GS, et al. Gain-of-function Pyrin mutations induce NLRP3 protein-independent interleukin-1 $\beta$ activation and severe autoinflammation in mice. Immunity. 2011;34(5):755-768.

19. Stehlik C, Reed JC. The PYRIN connection: novel players in innate immunity and inflammation. J Exp Med. 2004;200(5):551-558.

20. Uzar E, Evliyaoglu O, Yucel Y, et al. Serum cytokine and pro-brain natriuretic peptide (BNP) levels in patients with migraine. Eur Rev Med Pharmacol Sci. 2011;15(10):1111-1116.

21. Perini F, D’Andrea G, Galloni E, et al. Plasma cytokine levels in migraineurs and controls. Headache. 2005;45(7):926-931.

22. Ait-Idir D, Khilan A, Djerdjouri B, El-Shanti H. Spectrum of mutations and carrier frequency of familial Mediterranean fever gene in the Algerian population. Rheumatology (Oxford). 2011;50(12):2306-2310.

23. Çomak E, Tüfekçi Ö, Kılıçbay F, et al. Febrile seizures in children with familial Mediterranean fever: coincidence or association? Eur J Paediatr Neurol. 2015;19(5):572-576.

24. Federici S, Calcagno G, Finetti M, et al. Clinical impact of MEFV mutations in children with periodic fever in a prevalent western European Caucasian population. Ann Rheum Dis. 2012;71(12):1961-1965.

25. Kishida D, Nakamura A, Yazaki M, Tsuchiya-Suzuki A, Matsuda M, Ikeda S. Genotype-phenotype correlation in Japanese patients with familial Mediterranean fever: differences in genotype and clinical features between Japanese and Mediterranean populations. Arthritis Res Ther. 2014;16(5):439.

26. Coşkun S, Kurtgöz S, Keskin E, Sönmez F, Bozkurt G. Frequency of mutations in Mediterranean fever gene, with gender and genotypephenotype correlations in a Turkish population. J Genet. 2015;94(4): 629-635.

27. Yigit S, Inanir A, Karakus N, Kesici E, Bozkurt N. Common Mediterranean fever (MEFV) gene mutations associated with ankylosing spondylitis in Turkish population. Dis Markers. 2012;33(3):113-118.

28. Koca SS, Etem EO, Isik B, et al. Prevalence and significance of MEFV gene mutations in a cohort of patients with rheumatoid arthritis. Joint Bone Spine. 2010;77(1):32-35.

29. Karakus N, Yigit S, Inanir A, Inanir S, Toprak H, Okan S. Association between sequence variations of the Mediterranean fever gene and fibromyalgia syndrome in a cohort of Turkish patients. Clin Chim Acta. 2012;414:36-40.

30. Headache Classification Committee of the International Headache Society. The International Classification of Headache Disorders, 3rd edition (beta version). Cephalalgia. 2013;33(9):629-808.

31. Faul F, Erdfelder E, Lang AG, Buchner A. G*Power 3: a flexible statistical power analysis program for the social, behavioral, and biomedical sciences. Behav Res Methods. 2007;39(2):175-191.

32. Bigal ME, Liberman JN, Lipton RB. Obesity and migraine: a population study. Neurology. 2006;66(4):545-550. 
33. Stewart WF, Staffa J, Lipton RB, Ottman R. Familial risk of migraine: a population-based study. Ann Neurol. 1997;41(2):166-172.

34. Gedalia A, Zamir S. Neurologic manifestations in familial Mediterranean fever. Pediatr Neurol. 1993;9(4):301-302.

35. Centola M, Wood G, Frucht DM, et al. The gene for familial Mediterranean fever, MEFV, is expressed in early leukocyte development and is regulated in response to inflammatory mediators. Blood. 2000;95(10):3223-3231.

36. Duarte H, Teixeira AL, Rocha NP, Domingues RB. Increased interictal serum levels of CXCL8/IL-8 and CCL3/MIP-1 $\alpha$ in migraine. Neurol Sci. 2015;36(2):203-208.
37. Tunca M, Akar S, Onen F, et al. Familial Mediterranean fever (FMF) in Turkey: results of a nationwide multicenter study. Medicine (Baltimore). 2005;84(1):1-11

38. Yilmaz E, Ozen S, Balci B, et al. Mutation frequency of Familial Mediterranean Fever and evidence for a high carrier rate in the Turkish population. Eur J Hum Genet. 2001;9(7):553-555.

\section{Publish your work in this journal}

Neuropsychiatric Disease and Treatment is an international, peerreviewed journal of clinical therapeutics and pharmacology focusing on concise rapid reporting of clinical or pre-clinical studies on a range of neuropsychiatric and neurological disorders. This journal is indexed on PubMed Central, the 'PsycINFO' database and CAS, and is the official journal of The International Neuropsychiatric Association (INA). The manuscript management system is completely online and includes a very quick and fair peer-review system, which is all easy to use. Visit http://www.dovepress.com/testimonials.php to read real quotes from published authors.

Submit your manuscript here: http://www.dovepress.com/neuropsychiatric-disease-and-treatment-journal 